\title{
Pregnancy outcome following emergency cervical cerclage
}

\author{
Maheswari Srinivasan $^{1}$, Rajeshwari Navaneetha Krishanan ${ }^{2}$, S. W. Lindow ${ }^{3}$ \\ ${ }^{1}$ Specialist trainee in Obstetrics and Gynaecology, Heartlands Hospital, Birmingham, UK; \\ ${ }^{2}$ Specialist trainee in Obstetrics and Gynaecology, Hull Royal Infirmary, Hull, UK; \\ ${ }^{3}$ Senior Lecturer Perinatology, Hull Royal Infirmary, Hull, UK. \\ Email: Stephen.lindow@hey.nhs.uk
}

Received 11 October 2011; revised 15 November 2011; accepted 30 November 2011.

\begin{abstract}
The pregnancy outcome following emergency cervical cerclage for cervical dilatation is unclear. The case notes of pregnant women who underwent the procedure from January 1996 until December 2005 at Hull Royal Infirmary and Castle Hill Hospitals was analysed. This procedure prolonged pregnancy in all patients with the mean duration of 24 days. There were 10 live births and two still births. Among the $\mathbf{1 0}$ live births there were five neonatal deaths (perinatal mortality 583/1000). Neonatal outcome was universally poor if the initial cervical dilatation was more than $5 \mathrm{~cm}$. All patients should be informed of the survival rates before undergoing this procedure.
\end{abstract}

Keywords: Pregnancy Outcome; Cervical Cerclage

\section{INTRODUCTION}

Silent dilation of the cervix is a common cause of second trimester pregnancy loss and an obstetric treatment dilemma. Cervical cerclage using Macdonald's stitch is controversial with the risk of rupturing the membranes balanced against prolonging the pregnancy. Theoretically, the greater the dilation the less chance of success could be expected. However there is little data on which to base this assumption. The aim of this study is to review the pregnancy outcome of women who underwent cervical cerclage for cervical dilatation in the second trimester of pregnancy at Hull Royal Infirmary and Castle hill Hospital.

\section{MATERIALS AND METHODS}

The theatre registers of the Hull Royal Infirmary and Castle hill Hospital were reviewed from January 1995 until December 2005 to identify cases of cervical cerclage and the case notes were analysed. Subsequently a retrospecttive case note review was performed of women who underwent cervical cerclage for cervical dilatation of more than $3 \mathrm{~cm}$.
A standard proforma was completed on all cases and the data entered onto SPSS v 15 for statistical analysis.

\section{TECHNIQUE}

All women were treated pre-operatively in the trendelenberg position and bed rest for approximately 48 hours. An antibiotic (co-amoxiclav $625 \mathrm{mg} 8$ hourly) was prescribed in all cases and indomethacin $100 \mathrm{mg}$ per rectum given 12 hourly.

During the operation the patient was placed in a steep head down, lithotomy position. The membranes were replaced into the uterine cavity using a Foley catheter with a $30 \mathrm{ml}$ bulb and cerclage was carried out using MacDonald's technique with merselene tape.

Post operatively the antibiotic was continued to complete a 1 week course and Indomethacin was continued for $48 \mathrm{hr}$.

\section{RESULTS}

48 cases of cervical cerclage were carried out in the time period including 20 elective cervical cerclages performed between 14 weeks - 16 weeks and 28 emergency cervical cerclages performed between 16 weeks - 28 weeks. Of these 28 emergency cervical cerclages, 12 were performed for dilation of cervix while the remaining were performed for cervical shortening and U-shaped funnelling of the uterine cervix. The outcome of these 12 women who underwent an emergency cervical cerclage was analysed.

The mean gestational age at insertion was 22.6 days. The time interval between insertion of the cervical stitch and delivery ranged from 1 day - 90 days (mean 24 days).

There were 2 stillbirths, 10 live births of which 5 babies survived and 5 were neonatal deaths. The gestational age at delivery ranged between 22 weeks +4 days to 38 weeks. Better outcome of pregnancy was gained when the prolongation of pregnancy was more than 2 weeks amples of the type styles are provided throughout this document and are identified in italic type, within 


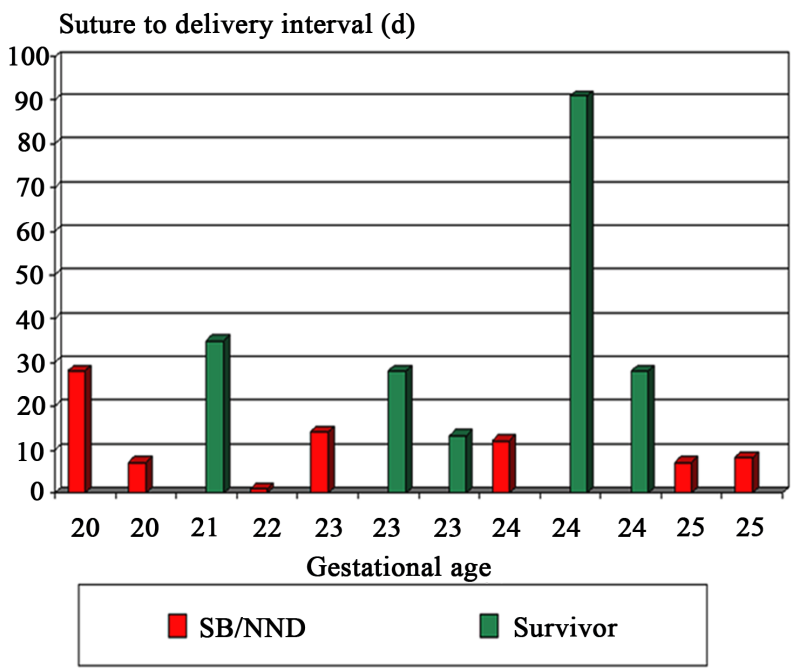

Figure 1. Gestational age at cerclage insertion (weeks) of the cerclage vs. suture to delivery interval (d) and pregnancy outcome.

parentheses, following the example. Some components, such as multi-leveled equations, graphics, and tables are not prescribed, although the various table text styles are provided. The formatter will need to create these components, incorporating the applicable criteria that follow. (Figure 1).

6 women presented with cervical dilatation of less than $5 \mathrm{~cm}$ at the time of cervical cerclage and 5 women had babies survived.

\section{DISCUSSION}

Emergency cervical cerclage for cervical dilation has been part of obstetric practice for many decades but it still remains a controversial decision. The responsible Obstetricians and the patients who present with painless dilation either have to wait for events or to undertake a procedure that by itself carries its own risk of rupturing the membranes and thus ending the pregnancy.

Groom et al (2001) published a successful pregnancy outcome in a woman with advanced cervical dilation in second trimester in which cervical cerclage was carried out replacing the membranes in the uterine cavity.

Ventolini et al (2009) presented cohort study between January 2003 until December 2005 of 68 women with cervical dilatation comprising 56 women with rescue cerclage and 12 women with expectant management. Median time from diagnosis to delivery was longer in the cerclage group (9.1 weeks) than in the expectant group (3.3 weeks $\mathrm{P}<0.01$ ). They concluded that cerclage is a better option in appropriately selected cases.

Kanai et al (2008) presented 5 cases of bulging membranes that were all replaced into the uterine cavity using a balloon and the mean prolongation of pregnancy was 77.6(d).
Cockwell et al (2005) presented 12 cases of emergency cerclage in which the mean prolongation of pregnancy was 7 weeks and 1 day with a neonatal survival of over $70 \%$. They concluded cervical cerclage is an option if women presented with dilated cervix in the second trimester.

Chasen et al (1998) published a retrospective review of 75 patients with non-prophylactic cervical cerclage and concluded that an advanced cervical dilation with bulging membranes at presentation was associated with lower cerclage-to-delivery intervals as well as a lower chance of reaching 28 weeks of gestation than lesser degrees of dilation and membrane bulging.

The studies presented conclude that cervical cerclage is indeed a therapeutic option in appropriately selected cases. There are no studies comparing the degree of cervical dilatationn to the pregnancy outcome. In our series we found that with advanced cervical dilatation the prolongation of pregnancy was only a few days and there were no neonatal survivors.

No randomised studies have been conducted regarding prophylactic cerclage versuss expectant management in women with dilatation of cervix. In our analysis we found cervical cerclage is possibly a better choice if the cervical dilatation at the time of cervical cerclage is less than $5 \mathrm{~cm}$. It is perhaps of limited use in performing a cerclage if the dilation is greater than $5 \mathrm{~cm}$.

Randomised controlled trials should be conducted in order to answer the question whether an emergency rescue cerclage has its benefits but in the meantime it should be left to the individual consultant to use their judgement.

\section{CONCLUSIONS}

Emergency cervical cerclage is a reasonable option for women who present with painless cervical dilatation of less than 5 cms. Patients should be advised of the poor outcome if the cervical dilation is more than $5 \mathrm{cms}$ if cervical cerclage is contemplated.

\section{DECLARATION OF INTEREST}

The authors report no declaration of interest.

\section{REFERENCES}

[1] Chasen, S.T. and Silverman, N.S. (1998) Mid-Trimester emergent cerclage: A ten year single institution review. Journal of Perinatology, 18, 338-342.

[2] Cockwell, H.A. and Smith, G.N. (2005) Cervical incompetence and the role of emergency cerclage. Journal of Obstetrics and Gynaecology Canada, 27, 123-129.

[3] Groom, K.M., Bennett, P.R., Maxwell, D.J. and Shennan, A.H. (2001) Successful cerclage at advanced cervical dilatation in the second trimester. International Journal 
of Obstetrics and Gynaecology, 108, 1005-1007.

[4] Kanai, M., Ashida, T., Ohira, S., Osada, R. and Konishi, I. (2008) A new technique using a rubber balloon in emergency second trimester cerclage for fetal membrane prolapse. Journal of Obstetrics and Gynaecology Re- search, 34, 935-940.

[5] Ventolini, G. and Neiger, R. (2009) Management of painless mid-trimester cervical dilatation: Prophylactic vs. emergency placement of cervical cerclage. Journal of Maternal-Fetal and Neonatal Medicine, 22, 510-516. 